\title{
Bill's bands
}

\section{Swiss sculptor Max Bill, working in the middle of this century, created forms aiming to visualize intuitively the mathematics of his day, with their structure determined by a sense of the way space could be 'energized'.}

\section{Martin Kemp}

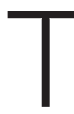

he idea that mathematical ideas can exhibit beauty, and more particularly that pure geometrical forms exhibit aesthetic perfection at the highest level, has an ancient ancestry. The figures of the five regular polyhedra - the so-called 'Platonic solids' - together with the sphere were particularly revered for their perfect symmetries, and became favourite objects in Renaissance decorative schemes such as the perspectival panels of inlaid wood that adorned aristocratic studios.

Writing in 1949 (ref. 1), the Swiss sculptor, painter and architect Max Bill (born 1908) delighted in the "aesthetic reaction" provoked by "models at the Musée Poincaré in Paris where conceptions of space have been embodied in plastic shapes or made manifest by coloured diagrams". With the advent of abstraction in classic Modernism in this century, such geometrical forms have been liberated to become self-sufficient subjects for autonomous works of art - and this is just what Bill exploited in his own sculpture.

He saw his works as presenting something analogous to the mathematics of his day; as a form of intuitive visualisation of "theorems" that were escaping the reach of any conventional "visualizing agency". He was striving for an art that would be to Einstein what the work of Phidias, the ancient Greek sculptor, was to Archimedes.

One series of sculptures, in a variety of media, works variations of the Möbius band, evoking the idea of a "finite infinity" which Bill characterized as an "essential guide to the speculations of contemporary physicists".

\section{The precise form adopted by Bill's} topological variations was determined not by mathem sense of the $w$ energized to re that may be ac' revealed, inchc which underlie and every law 1 power to fatho

His aim was than the constru of content baser sensing of the cr cance of "fields tion".

Bill was one number of a who were attem ing to respond

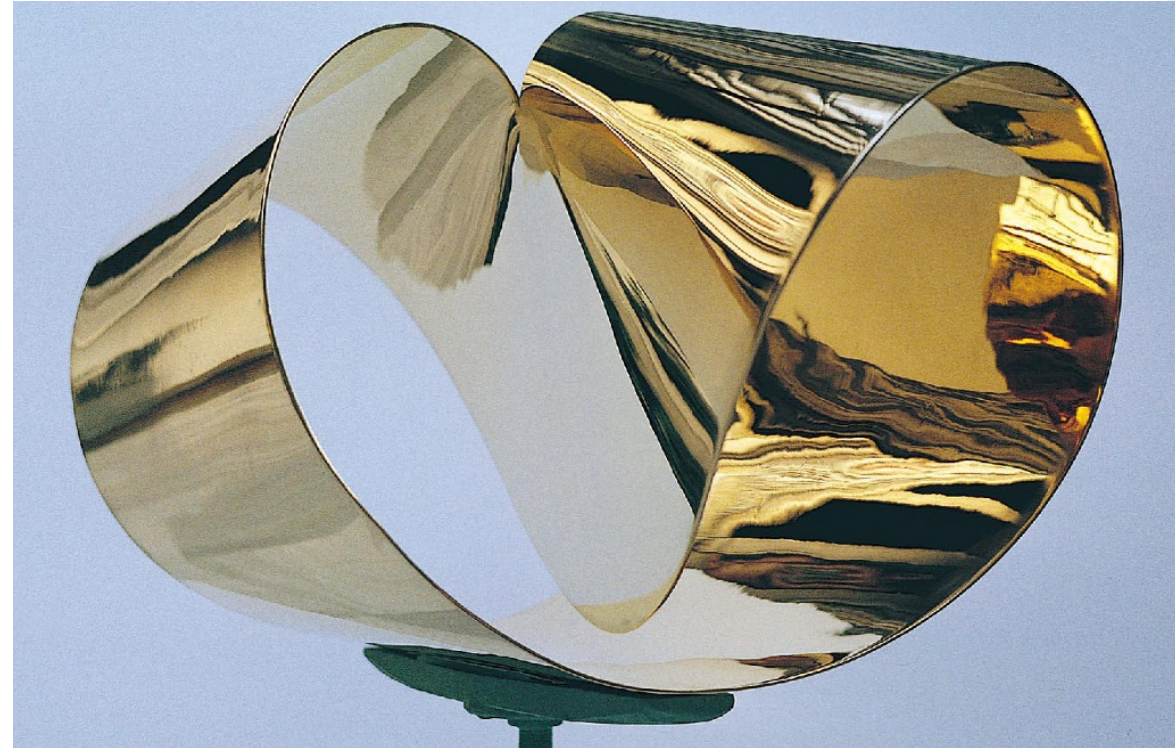

Max Bill's Monoangulated Surface in Space (gilded brass, 1959).

new ideas of space in physics and mathematics. They came face to face with the problem that besets anyone - artist or scientist who wishes to illustrate four- or multidimensional space with the resources available to us for representation in our two- and three-dimensional media. Basically, as I will be showing in a later article, the problem cannot be solved in terms of any model that we can really 'see'. The advantage that the artists possess is that they can exploit suggestion and visual allusion in a way that is not generally acceptable in a scientific or geometrical diagram. Bill felt free to elide geometry, aesthetics and metaphysics without the constraints of analytical accountability that dominate modern science. To most modern mathematicians, how- stands very much as an heir to the geometrical cosmographers of the past — not least to Johannes Kepler, the astronomer who in the early seventeenth century first established the elliptical nature of the planetary orbits.

Perhaps the unembarrassed nature of Bill's "astral flights... of the imagination" achieves something that modern science has striven to drive underground, giving the lie to the instinctual passions that motivate and sustain scientific enquiry in its most abstract and mathematically demanding forms. Should we now be condemned to segregate into separate mental zones faculties that past ages could see married in the work of one mind?

Martin Kemp is in the Department of the History of Art, University of Oxford, 35 Beaumont Street,

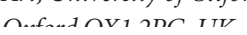



